\title{
(6) OPEN ACCESS \\ Cigarette prohibition and the need for more prior testing of the WHO TobReg's global nicotine-reduction strategy
}

\author{
Lynn T Kozlowski
}

\section{Correspondence to \\ Dr Lynn T Kozlowski, Department of Community Health and Health Behavior, School of Public Health and Health Professions, University at Buffalo, 323 Kimball Tower 3435 Main Street, Buffalo, NY 14214-8028, USA; lk22@buffalo.edu}

Received 18 February 2016 Accepted 13 May 2016 Published Online First 29 June 2016

\section{SLinked}

- http://dx.doi.org/10.1136/ tobaccocontrol-2016-053150 - http://dx.doi.org/10.1136/ tobaccocontrol-2016-053134

CrossMark

To cite: Kozlowski LT. Tob Control 2017;26:e31-e34.

\section{WHO STUDY GROUP ON TOBACCO PRODUCT REGULATION (TOBREG) ADVISORY NOTE RECOMMENDS GLOBAL NICOTINE-REDUCTION STRATEGY}

One can expect that the WHO Framework Convention on Tobacco Control (FCTC) Conference of the Parties may well be influenced by the recent WHO TobReg 'Advisory Note" ${ }^{1}$ that supports, albeit with a host of caveats, recommendations to implement product regulations requiring reduction of nicotine levels in cigarettes. ${ }^{2-4}$ Note that these cigarettes are not the same as conventional lower yield cigarettes that were subject to compensatory smoking that maintained tar and nicotine exposures to smokers. ${ }^{5}$ To quote from the report's conclusions, the first two 'regulatory recommendations' are:

- Mandated reductions in nicotine to minimally addictive levels should be supported by comprehensive regulation of all nicotine- and tobaccocontaining products.

- Mandated reductions in nicotine to minimally addictive levels must be part of comprehensive tobacco control, including increased taxes on cigarettes, comprehensive smoking bans, antismoking educational campaigns and graphic warning labels or plain packaging (ref. 1, p. 28).

The next four regulatory recommendations concern precautions related to how to do this in the context of comprehensive tobacco control. The Advisory Note and its conclusions clearly appreciate and assume that (1) the nicotine-reduced cigarette will be challenging to traditional smokers and (2) alternative sources of nicotine are likely to be needed, used and monitored. The last recommendation warns: 'A strategy to reduce the addictiveness of tobacco is not recommended in the absence of developed capacity for market surveillance and product testing.' (ref. 1, p. 29).

\section{RESEARCH TO DATE}

The recent, high-profile, randomised controlled trial is arguably the most substantial study until now and has been viewed as supportive, but one should look at it closely and critically. ${ }^{6}$ The report's introduction summarises the prior literature: 'The results of several relatively small studies suggest [emphasis added] that cigarettes with very low nicotine content are associated with a desirable set of outcomes...' (p. 1341). The article itself concludes: 'This study provides preliminary short-term data suggesting (emphasis added) that as compared with the nicotine content of conventional cigarettes, a substantial reduction in nicotine content is associated with reductions in smoking, nicotine exposure, and nicotine dependence, with minimal evidence of nicotine withdrawal, compensatory smoking, or serious adverse events' (p. 1349). The clinical significance of any of the statistically reliable effects ranges from unclear to doubtful. For example, changes of about 0.5 units in the Fagerström Test for Nicotine Dependence (FTND) ${ }^{7}$ would not be expected to have any clinical importance for cessation. ${ }^{8}{ }^{9}$ The study was not designed to assess smoking cessation or the effects of use of alternative nicotine sources (as has been recognised as an overall component of the strategy).

The authors acknowledge that their sample was not representative of smokers in the USA, in part from excluding individuals with serious physical or mental disorders or who used any illicit drugs (except marijuana). Individuals with mental illness are more likely to be smokers, be more nicotine dependent and have a harder time quitting; these individuals account for $40-50 \%$ of the cigarettes consumed, despite being only $28 \%$ of the population. ${ }^{10}{ }^{11}$ Analyses of more representative US data find that mental illness was associated with a much greater likelihood of nicotine withdrawal and estimate that $44 \%$ of nicotine withdrawal syndrome diagnoses are attributable to mental illness. ${ }^{12}$ It is, of course, not surprising or inappropriate that preliminary research would focus on healthy samples initially. However, given the recognised health disparities in smokers and the connections between smoking, mental illness, and use of alcohol and other substances, it should be important to assess the effects on such groups of restrictions to only very low-nicotine cigarettes, before recommending governmental regulations for all.

The authors note that 'use of non-study cigarettes was common', and explicitly acceptable, though discouraged, but also indicated as happening more often when on reduced-nicotine cigarettes. The up to US $\$ 835$ payment for participation was structured so that if one dropped out after screening, one received only US $\$ 25$, with increasing rewards for each type of session based on length. By completing all sessions and being timely, participants received a US $\$ 200$ bonus (making the maximum payment US\$835). Free cigarettes can be seen as an added financial incentive. Such an incrementally rewarded (a standard practice), nonmandatory, 6-week opportunity for healthy volunteers to try low-nicotine cigarettes does not really simulate what would happen if a representative 
group of smokers, some of them poor, had to pay themselves for only low-nicotine cigarettes with no legal access to their usual cigarettes.

No study that I know of has been done on how a representative sample of adult smokers experiencing mandatory lownicotine cigarettes would respond, and the existing research on biased samples of well-compensated, healthy volunteers is described by the authors themselves as 'preliminary' and 'suggesting' good outcomes. On balance, it is very hard to see that we are close to having an evidence base that would support any government to embark on implementation of a mandatory regulation for all their smokers-no matter how advanced their tobacco control programming.

\section{CALLING A CIGARETTE PROHIBITION A CIGARETTE PROHIBITION}

The low-nicotine cigarette now being tested by the US Food and Drug Administration (FDA) was on the market in the USA for several years, and it has been judged a commercial failure despite extensive promotion (eg, US $\$ 20$ million in advertising). ${ }^{13}$ Nicotine-reduced cigarettes were not very appealing to consumers and were not overall a preferred product. ${ }^{15} 15$ Although not conclusive, this experience does raise questions about how such a product would be received as the only legal cigarette.

The terms of the US FDA tobacco law encourage the view that cigarette nicotine reduction is a way to regulate the addictiveness out of cigarettes without actually banning them. ${ }^{16}$ The law both forbids the banning of cigarettes and also appears to explicitly authorise the reduction of nicotine levels in cigarettes as long as they do not make it 'zero' nicotine (see ref. 17 for a discussion of the complexity of the FDA law). Outside the framework of the law, it may be easier to accept a more commonsensical perspective. If one subverts the functions of a drugdelivery system (the cigarette) by reducing the active drug dose to ineffective levels, this is fundamentally a banning of the consumer-preferred conventional cigarette. For those who seek the psychoactive effects of nicotine in cigarettes, the mandatory low-nicotine cigarette is a ban of their preferred product.

Popular recreational drug-delivery systems come in particular forms for which users can have very strong attachments. Imagine non-decaffeinated coffee lovers who were told that they must switch to tea (or vice versa) because of a newly discovered health risk if they wanted to continue safely having significant doses of caffeine. The coffee lovers might well consider themselves prohibited from buying 'real' coffee; or consider social drinkers who enjoy the psychoactive effects of wine or beer or liquor, preferring one form over the others. How would they react to regulations that forbid access to their preferred alcoholcontaining beverage? Some drinkers might not care very much, but some would care a great deal and would see it as a banning of their preferred form of alcohol use. If the dose of the active ingredient in a preferred product is reduced to only ineffective levels, the preferred product has in effect been banned.

\section{PROHIBITION OF CONVENTIONAL CIGARETTES WOULD BE A MAJOR STEP IN TOBACCO CONTROL QUITE UNLIKE THE MAINSTAYS OF TOBACCO CONTROL}

While some tobacco control interventions have been implemented without any prior assessment of the impact on communities overall, these interventions did not involve a proposed degradation of a key active ingredient in cigarettes. For example, putting a cigarette in a plain package or putting a graphic warning label on it does not change the product itself. Even banning flavours leaves the drug-delivery system fundamentally unimpaired. The nicotine-reduction policy needs to be assessed in some actual societal context in a full range of smokers to be able to project the impact of such a regulatory policy that has never been tested in the real world. A recent assessment of the USA illicit tobacco market, which included some consideration of the nicotine-reduction research, concluded that the findings were 'suggestive, not conclusive'. ${ }^{18}$ Many of the elements described in the second bullet point above from the Advisory Note have actually been assessed under real-world conditions. ${ }^{19}$ For example, there is a rich empirical sense of how taxes work to influence sales in actual communities, ${ }^{20}$ and that higher taxes can also promote black market sales. ${ }^{21}$ One of the lessons of tobacco taxation is that consumers will pay a great deal to obtain this desired product. One should expect that a number of consumers will pay the personal and financial costs for contraband conventional cigarettes.

\section{HOW WOULD LOW-NICOTINE CIGARETTE REGULATIONS ACTUALLY WORK?}

The TobReg report did indicate several important considerations for implementation (p. 26), including the need for complex surveillance systems with accompanying efforts to reduce contraband and smuggling as well as the importance of making available acceptable alternative forms of nicotine. It is understandable that their report would not go into great detail on implementation issues, but other questions are worth noting here. What would the law and its enforcement look like? Would sales, purchase or possession be prohibited? Would there be fines or incarceration? What priority would police or courts give to this issue? How hard would it be to distinguish legal cigarettes from illegal cigarettes? Would the legal tax base (that might support tobacco control) plummet? What sort of crime networks and economies might develop to supply smokers who prefer not to use reduced-nicotine cigarettes or switch to less harmful nicotine products (the market for which can differ greatly across countries)? The Advisory Note admits: 'No published study has provided an estimate of the probable illicit sales of conventional cigarettes with a higher nicotine content in the context of a reduced-nicotine market.' Some may view illicit trade as something that the tobacco industry has been willing to support. Be that as it may, one needs to consider the human predicament of the smoker who wants the product in the context of alternative tobacco/nicotine product markets that are likely to be quite different from country to country.

Countries differ in the array of legal nicotine delivery systems they offer. A reduced-nicotine cigarette in Sweden, for example, might spur the use of snus (a lower toxin tobacco product), but in most of the European Union, snus is banned. In India a push arising from reduced-nicotine cigarettes could encourage the increased use of indigenous, smokeless tobacco products that are more highly toxic than snus. The Advisory Note does ask for surveillance and epidemiological work, but these are likely to be limited tools in the face of a possibly fast-moving social experiment with economic, health and legal implications.

Consider two scenarios. In the first, you are in charge of tobacco control in a country that has instituted a plain packaging law, but your neighbouring countries have not done so. Would you be worried about cross-border issues arising from the smuggling of cigarettes in traditional branded packs (the exact same cigarette you sell in plain packs)? Probably not so much. However, would you answer the same if you were instituting mandatory reduced-nicotine cigarettes and your neighbours were not? 
Before moving to make traditional cigarettes an illegal drug product, it could be instructive to study the international experience with cannabis, which has been described as the most widely used 'illegal' drug globally in $2012 .^{22}$ If the nicotinereduction model were widely adopted, traditional cigarettes could become one of the world's most widely used 'illegal' drug products. A recent analysis of the options of prohibition, decriminalisation and legalisation of cannabis (noting that prohibition is currently the dominant model globally) recommends that 'legalisation with strict regulation' is the superior option for public health in 'high income countries in North America'. ${ }^{23}$ These authors also note that in addition to health harms caused by cannabis: 'Under a system of prohibition, the enforcement of cannabis laws results in extensive costs, and in high levels of arrests and criminal records in the population.'(p. 42). One might suppose that no one is anticipating criminal records for possession of conventional cigarettes, but it does raise the question of the need to know what exactly would be proposed and how it would work (or be ignored) in a community.

\section{LESSONS FROM ALCOHOL PROHIBITION IN THE USA}

Experts have drawn several and sometimes conflicting conclusions from the experience of alcohol prohibition (and its repeal) in the USA. ${ }^{24}{ }^{25}$ Whether one judges alcohol prohibition in some or all respects a success or failure, it is clear that implementation of prohibition created surprises for many of those involved. ${ }^{26}$

Those who moved to ban alcohol in the USA did so with no good sense of the societal consequences. Similarly, those recommending that FCTC countries adopt a nicotine-reduction strategy demonstrate relatively little concern for the possible negative societal consequences. Hall ${ }^{25}$ provides a scholarly review and concludes that the extensive prohibition of alcohol may have caused more harm than good, but that 'limited prohibitions' are probably very valuable. His example of a 'limited prohibition' is placing prohibitions on the legal age for purchasing alcohol. Indeed, such a 'limited prohibition' has been used, studied and found to be a valuable tobacco control tool. ${ }^{27} 28$

\section{FIRST, IF ANY COUNTRY DOES IT, A COUNTRY WITH STRONG TOBACCO CONTROLS SHOULD TRY IT AND EVALUATE IT}

The Advisory Note cautions that the nicotine-reduction strategy is 'not recommended' if a country's tobacco control system is not advanced. This caution needs to be much stronger. Even an established, well-resourced, state-of-the-art tobacco control system needs to be prepared for a prohibition on conventional cigarettes that could have serious societal consequences, possibly resulting in a costly battle over and withdrawal of the law, either because of public objections or because of net negative effects on public health, especially in those portions of society facing the greatest health disparities. Until such time as a country or two with extensive, effective and comprehensive tobacco control programming has evaluated its real-world experience with the costs and benefits of such a strategy, other countries should be advised against attempting this regulation which as yet has been tried in no community.

Medical and scientific research is one element of policy development, especially if done on representative samples, but it can be critical to see the impact of policies in the complex systems that are communities. In a recent review of cannabis policy, it was noted that the circumstances of countries can differ greatly and that (1) policies should be developed that can 'learn' and change depending on how they are working and (2) one should be systematically learning from the experience of early adopters of a policy. ${ }^{29}$

\section{GOING BEYOND THE APPEARANCE OF CONFLICT OF INTEREST}

The TobReg committee members who are likely to be the most knowledgeable on nicotine reduction have been long-standing supporters of the strategy, ${ }^{2}$ and their positive recommendation for dissemination may be unsurprising as well as would be some possible deference by other committee members or reviewers to the opinions of these experts. These members include Jack Henningfield (the proposal's cocreator), ${ }^{2-4}$ Dorothy Hatsukami, ${ }^{6}{ }^{30}$ David Ashley (an FDA scientist/administrator involved with its tobacco law that explicitly requires assessment of this proposal) and the late Nigel Gray. ${ }^{31}$ Given that I have also published on what I consider to be unlikely prospects for and advisability of mandatory nicotine-reduction regulation in the USA, despite its apparently privileged position in FDA tobacco law, ${ }^{17}$ it might be equally unsurprising that I raise issues. None of this background for any one of us should be used to discount the positions taken, but readers should be mindful of the need to think carefully for themselves about the issues. ${ }^{32}$

\section{CONCLUSIONS}

The reduced-nicotine cigarette strategy is an idea that is more elegant and attractive to some than others ${ }^{17} 33$ and on which the USA is investing millions of dollars in research. Some of the attraction most likely arises from the prospect of 'banning' cigarettes (without, according to the FDA framework, actually banning them) and from the elimination of the much feared 'gateway effect' by removing addictive cigarettes as an option for youth or adults. ${ }^{17}$ Nevertheless, a prior condition for disseminating even an appealing regulation that would act as a prohibition of the most popular tobacco product should be the support of a persuasive evidence base and assessment in communities of free-roaming individuals. The research on the low nicotine-reduction recommendation is until now preliminary and suggestive and not on representative samples of smokers. We have no direct evidence showing that it works to promote public health in any community anywhere. Such an untested community-level product prohibition is inappropriate for widespread dissemination by evidence-based health organisations. The amount of money for tobacco control is always limited, and it is premature to seek a formal place for the nicotine-reduction regulation within comprehensive tobacco control. Standard tobacco control measures (such as age restrictions, taxes, cessation supports, public smoking bans) have been tried in a number of places and have a persuasive evidence base. Even lower harm products such as vaping products and snus are providing some evidence of how they work in communities. ${ }^{35-37}$ Programmes to 'do good' have regularly arisen from simplified models of what a community needs and major mistakes can result. $^{38}$ If no high-functioning comprehensive tobacco control programme is prepared to assess the nicotine-reduction strategy as regulatory policy, especially in the light of the currently only preliminary evidence in limited samples, then it should sit on the shelves and not be disseminated as a call for action.

\section{Competing interests None declared.}

Provenance and peer review Not commissioned; externally peer reviewed.

Open Access This is an Open Access article distributed in accordance with the Creative Commons Attribution Non Commercial (CC BY-NC 4.0) license, which permits others to distribute, remix, adapt, build upon this work non-commercially, and license their derivative works on different terms, provided the original work is 
properly cited and the use is non-commercial. See: http://creativecommons.org/ licenses/by-nc/4.0/

\section{REFERENCES}

1 World Health Organization Study Group of Tobacco Product Regulation. Advisory note: global nicotine reduction strategy. Geneva, Switzerland: World Health Organization, 2015. http://www.who.int/tobacco/publications/prod_regulation/ nicotine-reduction/en

2 Benowitz NL, Henningfield JE. Establishing a nicotine threshold for addiction. The implications for tobacco regulation. N Eng/ I Med 1994;331: 123-5.

3 Henningfield JE, Benowitz NL, Connolly GN, et al. Reducing tobacco addiction through tobacco product regulation. Tob Control 2004;13:132-5.

4 Benowitz NL, Henningfield JE. Reducing the nicotine content to make cigarettes less addictive. Tob Control 2013;22(Suppl 1):i14-17.

5 National Cancer Institute. Risks associated with smoking cigarettes with low machine-measured yields of tar and nicotine, Smoking and Tobacco Control Monograph 13. Bethesda, Maryland: US Department of Health and Human Services, National Cancer Institute, 2001.

6 Donny EC, Denlinger RL, Tidey JW, et al. Randomized trial of reduced-nicotine standards for cigarettes. N Engl J Med 2015;373:1340-9.

7 Heatherton TF, Kozlowski LT, Frecker RC, et al. The test for nicotine dependence: a revision of the Fagerström Tolerance Questionnaire. $\mathrm{Br} J$ Addict 1991;86:1119-27.

8 Kozlowski LT, Porter CQ, Orleans CT, et al. Predicting smoking cessation with self-reported measures of nicotine dependence: FTQ, FTND, and HSI. Drug Alcohol Depend 1994:34:211-16.

9 Fagerstrom K, Russ C, Yu CR, et al. The Fagerström Test for Nicotine Dependence as a predictor of smoking abstinence: a pooled analysis of varenicline clinical trial data. Nicotine Tob Res 2012;14:1467-73.

10 Lasser K, Boyd JW, Woolhandler S, et al. Smoking and mental illness: a population-based prevalence study. JAMA 2000;284:2606-10.

11 Grant BF, Hasin DS, Chou SP, et al. Nicotine dependence and psychiatric disorders in the United States: results from the national epidemiologic survey on alcohol and related conditions. Arch Gen Psychiatry 2004;61:1107-15.

12 Smith PH, Homish GG, Giovino GA, et al. Cigarette smoking and mental illness: a study of nicotine withdrawal. Am J Public Health 2014;104:e127-33.

13 Seeking Alpha. 22nd Century Group: a lot of smoke, not enough fire. 2014. http://www.nasdaq.com/article/22nd-century-group-a-lot-of-smoke-not-enough-firecm384624\#ixzz3KgTgBM2p

14 Caraballo RS, Pederson LL, Gupta N. New tobacco products: do smokers like them? Tob Control 2006;15:39-44.

15 Breland AB, Kleykamp BA, Eissenberg T. Clinical laboratory evaluation of potential reduced exposure products for smokers. Nicotine Tob Res 2006;8:727-38.

16 Family Smoking Prevention and Tobacco Control Act, Pub L 111-31, 123 Stat 1776 21 United States Code, 2009.

17 Kozlowski LT. Prospects for a nicotine-reduction strategy in the cigarette endgame: alternative tobacco harm reduction scenarios. Int J Drug Policy 2015;26:543-7.
18 Reuter P, Majmundar MK, National Research Council (U.S.). Committee on the Illicit Tobacco Market, et al. Understanding the U.S. illicit tobacco market: characteristics, policy context, and lessons from international experiences. Washington DC: National Academies Press, 2015.

19 Jha P, Chaloupka FJ. Curbing the epidemic: governments and the economics of tobacco control. World Bank Publications, 1999

20 Chaloupka FJ, Cummings KM, Morley CP, et al. Tax, price and cigarette smoking: evidence from the tobacco documents and implications for tobacco company marketing strategies. Tob Control 2002;11:i62-72.

21 Joossens L, Raw M. Progress in combating cigarette smuggling: controlling the supply chain. Tob Control 2008;17:399-404.

22 United Nations Office on Drugs and Crime (UNODC). World Drug Report 2014. Vienna: United Nations Office on Drugs and Crime, 2014.

23 Rehm J, Fischer B. Cannabis legalization with strict regulation, the overall superior policy option for public health. Clin Pharmacol Ther 2015;97:541-4

24 Blocker IS Jr. Did prohibition really work? Alcohol prohibition as a public health innovation. Am J Public Health 2006;96:233-43.

25 Hall W. What are the policy lessons of National Alcohol Prohibition in the United States, 1920-1933? Addiction 2010;105:1164-73.

26 Harp S. Globalization of the U.S. black market: prohibition, the war on drugs, and the case of Mexico. NY Univ Law Rev 2010;85:1661-93.

27 Kozlowski LT. A policy experiment is worth a million lives. Issues Sci Technol 2016;32:20-3.

28 Bonnie RJ, Stratton K, Kwan LY, et al. Public health implications of raising the minimum age of legal access to tobacco products. Washington DC: The National Academies Press, 2015.

29 Kleiman MAR, Ziskind J. Lawful access to cannabis: gains, losses and design criteria. In: LSE Expert Group on Economics of Drug Policy, ed. Ending the drug wars: report of the LSE expert group on the economics of drug policy. London: London School of Economics, 2014:77-81.

30 Hatsukami DK, Benowitz NL, Donny E, et al. Nicotine reduction: strategic research plan. Nicotine Tob Res 2013;15:1003-13.

31 Gray N, Borland R. Research required for the effective implementation of the Framework Convention on Tobacco Control, articles 9 and 10. Nicotine Tob Res 2013;15:777-88.

32 Kozlowski LT. Coping with the conflict-of-interest pandemic by listening to and doubting everyone, including yourself. Sci Eng Ethics 2016;22:591-6.

33 Jarvis MJ, Bates C. Eliminating nicotine in cigarettes. Tob Control 1999;8:106-7; author reply 107-9.

34 Shatenstein S. Eliminating nicotine in cigarettes. Tob Control 1999;8:106; author reply 107-9.

35 Foulds J, Ramstrom L, Burke M, et al. Effect of smokeless tobacco (snus) on smoking and public health in Sweden. Tob Control 2003;12:349-59.

36 Ramstrom LM, Foulds J. Role of snus in initiation and cessation of tobacco smoking in Sweden. Tob Control 2006;15:210-14.

37 Lund I, Lund KE. How has the availability of snus influenced cigarette smoking in Norway? Int J Environ Res Public Health 2014;11:11705-17.

38 Scott JC. Seeing like a state: how certain schemes to improve the human condition have failed. New Haven: Yale University Press, 1998. 